\title{
Amount of reinforcer and differentiation of response force
}

\author{
JOHN V. HARRELL and STEPHEN C. FOWLER \\ University of Mississippi, University, Mississippi 38677
}

\begin{abstract}
Three groups of 11 rats each were reinforced with one, two, or three 45-mg food pellets for responses having peak forces which fell within a 10- to $15 \mathrm{~g}$ force band. Other recorded responses above the 4-g response threshold were not reinforced. Measures of force differentiation performance, such as standard deviation of peak force and proportion of responses in band, showed that rate of differentiation learning and precision of force emission achieved increased with increasing amounts of reinforcer. These results are consistent with previous descriptions of the relationship between amount of reinforcer and force emission.
\end{abstract}

DiLollo, Ensminger, and Notterman (1965) reported that rats which receive large amounts of reinforcer emit operant response forces more closely approximating the minimum force criterion for reinforcement than do rats which receive smaller amounts of reinforcer. Variability of response force was also found to be inversely related to amount of reinforcer. On the basis of these results, DiLollo et al. (1965) concluded that the primary effect of the amount variable is to influence the precision of force emission. Moreover, it was proposed that force differentiation could be seen as a special case of discrimination learning based on interoceptive cuesa view for which evidence is accumulating (Ferraro \& Grilly, 1970; Notterman \& Mintz, 1965; Rickert, 1969). Since larger reinforcers usually produce more rapid learning of simple discriminations (Mackintosh, 1974), rats are better able to emit forces nearer the criterion for reinforcement because the larger amounts of reinforcer result in a more precise discrimination of the interoceptive cues that accompany emission of criterion forces. Despite the apparent soundness of this interpretation of the cited force differentiation data, two specific empirical considerations call it into question. First, because deprivation was defined in terms of 1-h daily access to food, and since amount of reinforcer delivered in a session differed substantially among groups (.7 $\mathrm{g}$ to $3.5 \mathrm{~g}$ per session), the groups may have been at different deprivation levels. This is important because Notterman and Mintz (1965, Chapter 10) demonstrated that, other things being equal, an increase in food deprivation results in higher levels of force emission. A second methodological problem involved the differentiation requirement. DiLollo et al. (1965) used a force criterion of $8 \mathrm{~g}$, but did not place upper

Reprint requests should be addressed to S. C. Fowler, Department of Psychology, University of Mississippi, University, Mississippi 38677 . This research was supported in part by the Committee on Faculty Research of the Graduate School of the University of Mississippi. limits on the forces that were reinforced. Such a procedure is at variance with methods commonly used in differentiation research, where response values must fall within specified lower and upper limits in order to be reinforced (Ferraro \& Grilly, 1970; Notterman \& Mintz, 1965; Platt, Kuch, \& Bitgood, 1973).

As a consequence of the foregoing methodological considerations, the present experiment was undertaken as a partial replication of the study by DiLollo et al. (1965). To avoid confounding amount of food reinforcer and deprivation, the rats were maintained at a relatively constant $80 \%$ of their free-feeding body weight. In accord with conventional differentiation paradigms, only responses having forces within specified lower and upper force limits (i.e., a force band) were reinforced.

\section{METHOD}

\section{Subjects}

The subjects were 33 male Sprague-Dawley (Holtzman) rats weighing approximately 250 to $300 \mathrm{~g}$. The rats were housed individually with water ad lib. Body weight was maintained at $80 \%$ of the free-feeding weight by daily feedings which occurred about $1 \mathrm{~h}$ after the experimental session.

\section{Apparatus}

All sessions were carried out in an experimental chamber constructed of Plexiglas and stainless steel, measuring $24 \times 20 \mathrm{x}$ $20 \mathrm{~cm}$. The floor was made of stainless steel rods running parallel to the front of the chamber, where the manipulandum and food cup were located. The chamber was enclosed within a soundattenuating wooden box which was ventilated by an electric blower. Illuminating the chamber was a $6-\mathrm{W}$ bulb located on the center of the front panel, $3.8 \mathrm{~cm}$ from the top. A rectangular opening, equidistant from each wall and measuring $3.2 \mathrm{~cm}$ wide and $2.2 \mathrm{~cm}$ high, was located on the front panel, $4.5 \mathrm{~cm}$ from the floor. This aperture permitted access to the isometric silent, force-sensing manipulandum, which was positioned $2.2 \mathrm{~cm}$ outside the chamber. A Hewlett-Packard force transducer (Model FTA-100) served as the force-sensing element. The manipulandum was an aluminum disk $18 \mathrm{~mm}$ in diam, oriented in the horizontal plane. The surface of the disk was $5 \mathrm{~mm}$ above the lower edge of the rectangular aperture in the chamber wall. Because the manipulandum was silent and practically isometric, 
neither auditory nor displacement cues were available during response emission.

Reinforcers, 45-mg food pellets, were dispensed by a Gerbrands feeder at a rate of 10 pellets/sec. Programming of contingencies and data recording were accomplished with a PDP-8/E computer interfaced to an A/D converter and a magnetic tape recorder. For details see Fowler (1974) and Fowler and Leberer (1977).

\section{Procedure}

Subjects were randomly assigned to three groups of 11 each. The groups were designated GP1, GP2, and GP3 to indicate the number of $45-\mathrm{mg}$ food pellets to be used as the reinforcer throughout all phases of training. A group to serve as a control for number of pellets vis a vis amount of reinforcer per se was not included because DiLollo et al. (1965) found no differences in force emission based on this procedural variable. Training began with two magazine sessions, one per day, in which each subject received 50 reinforcing events according to a variabletime 30 -sec schedule. The reinforcing events were one, two, or three pellets for GP1, GP2, and GP3, respectively. Following magazine training, each rat was shaped to reach through the opening in the front panel and press on the manipulandum. The operandum was initially placed flush with the front panel and was manually withdrawn, over the course of two sessions, until it was at its final position $(2.2 \mathrm{~cm}$ from the center of the disk to the outside of the chamber wall). This spatial arrangement insured that the animal could make responses only by pressing with its paws. During shaping sessions, all responses above the system threshold of $4.0 \mathrm{~g}$ were reinforced.

Acquisition sessions commenced on the day following shaping and continued for 15 daily sessions. Each subject received 50 reinforcing events per session, with the number of food pellets received per event being one, two, or three according to group assignment. During differentiation training, reinforcement was delivered for responses having peak forces falling between 10 and $15 \mathrm{~g}$ inclusive. All other responses (less than $10 \mathrm{~g}$ but greater than or equal to $4 \mathrm{~g}$ and responses greater than $15 \mathrm{~g})$ were not reinforced, although they were recorded. Reinforcement occurred only upon the completion of a response.

Three dependent variables provided measures of the subjects' performance during the force-band training. These were mean peak force, standard duration of peak force, and proportion of responses falling within the force band.

\section{RESULTS AND DISCUSSION}

Despite the graphic separation among groups seen in Figure 1 (Panel A) for the mean peak force variable, amount of reinforcer did not have a significant main effect on this measure $[F(2,30)=1.85, p>.10]$. However, both the training and interaction effects were statistically significant $[F(14,420)=22.75, p<.01$ for training; $F(28,420)=3.03, p<.01$ for interaction] . The latter test statistics confirm the pictorial impression given by Figure 1 (Panel A) that peak force was initially high but declined with reinforced practice and that the degree of decrease in peak force depended upon the amount of reinforcer used.

Variability of force emission, as measured by standard deviation of peak force (see Figure 1, Panel B) for each subject, was significantly influenced by amount of reinforcer $[\mathrm{F}(2,30)=5.61, \mathrm{p}<.01]$, by training $[F(14,420)=10.52, p<.01]$, and by the interaction of Amount by Training $[\mathrm{F}(28,420)=2.86, \mathrm{p}<.01]$.
Amount, training, and interaction effects were likewise significant for proportion of responses falling within the force band (see Figure 1, Panel C) $[\mathrm{F}(2,30)=4.33$, $\mathrm{p}<.025 ; \mathrm{F}(14,420)=19.98, \mathrm{p}<.01 ; \mathrm{F}(28,420)=2.15$, $\mathrm{p}<.01$, respectively]. Both the standard deviation and the proportion of in-band responses may be taken as
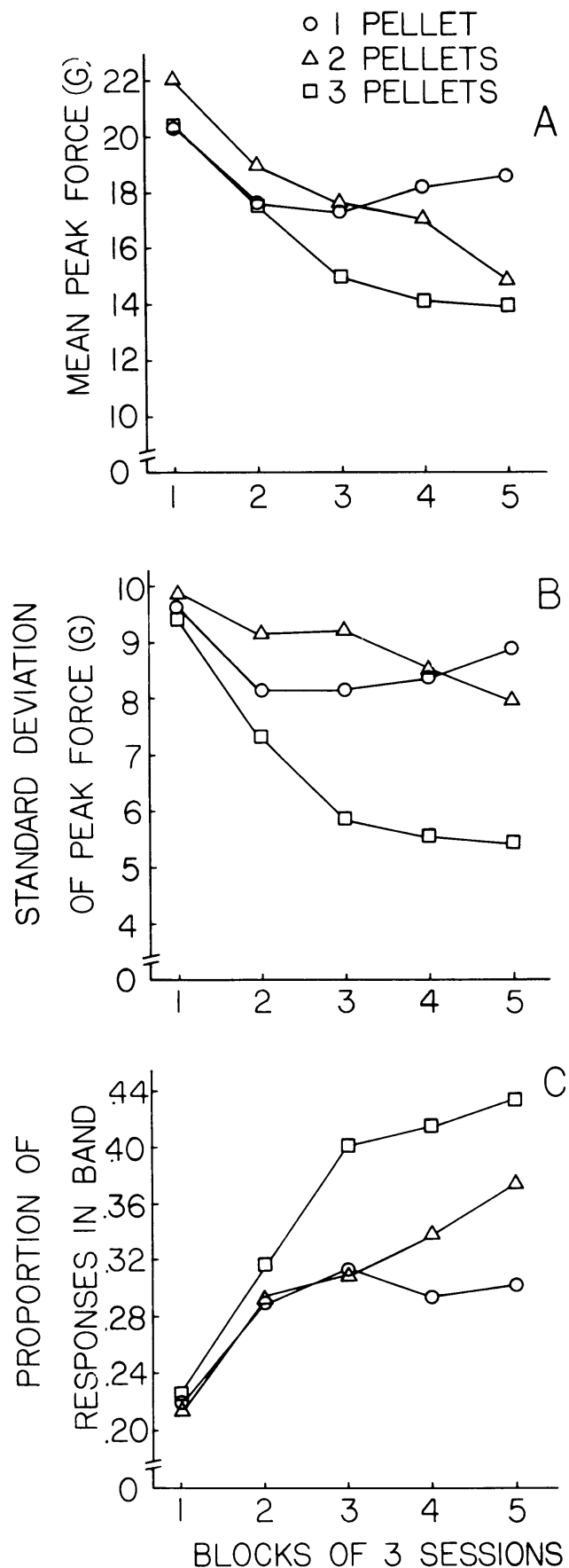

Figure 1. Mean peak force (A), standard deviation of peak force (B), and proportion of responses in band (C) as joint functions of sessions of training and amount of reinforcer. 
measures of precision of force emission, and the pattern of results for these variables clearly supports the hypothesis that amount of reinforcer promoted the rate of differentiation learning and influenced the final level of force differentiation achieved by the end of 15 sessions. Larger amounts of reinforcer engendered more precise force emission.

Overall, the results are consistent with the findings of DiLollo et al. (1965). These data also extend the generality of Mackintosh's (1974) conclusion about the effects of reinforcer magnitude: Larger reinforcers produce more precise force differentiation, just as they facilitate the acquisition of a simple discrimination.

It is interesting to note that reports concerning the effects of reinforcer magnitude on differentiation of response duration or interresponse time are less clear than those described here (Gibbon, 1977). The reason for this discrepancy may lie in the nature of the interoceptive cues used during the differentiation task. In a force differentiation task implemented with a silent, isometric operandum, the force cues available to the subject are generated in the stretch and tension receptors of the musculoskeletal system. On the other hand, the sensory receptors and correlated interoceptive cues used in a timing differentiation are less easily specified.

\section{REFERENCES}

Dilollo, V., Ensminger, W. D., \& Notterman, J. M. Response force as a function of amount of reinforcement. Journal of Experimental Psychology. 1965, 70, 27-31.

Ferraro, D. P., \& Grilly, D. M. Response differentiation: A psychophysical method for response-produced stimuli. Perception \& Psychophysics, 1970, 7, 206-208.

FowlER, S. C. A minicomputer system for recording the dynamic properties of individual operant responses. Behavior Research Methods \& Instrumentation, 1974. 6. 288-292.

Fowler, S. C., \& Leberer, M. R. Hardware techniques for analog processing using the State Systems PDP-8 I/O interface. Behavior Research Methods \& Instrumentation, 1977. 9. 210-214.

GibBon, J. Scalar expectancy theory and Weber's law in animal timing. Psychological Review, 1977, 84, 279-325.

Mackintosh, N. J. The psychology of animal learning. New York: Academic Press. 1974.

Notterman, J. M., \& Mintz, D. E. Dynamics of response. New York: Wiley, 1965.

Platt, J. R., Kuch, D., \& Bitgood, S. C. Rats' leverpress durations as psychophysical judgments of time. Journal of the Experimental Analysis of Behavior, 1973. 19. $239-250$.

Rickert. E. J. Role of feedback stimuli in response discrimination and differentiation. Journal of Experimental Psychology, 1969, 82, 148-155.

(Received for publication June 22. 1977.) 